\title{
The Notch pathway mediates the angiotensin II-induced synthesis of extracellular matrix components in podocytes
}

\author{
MIN YAO $^{1,2}$, XIAOMEI WANG ${ }^{1}$, XIAOMENG WANG $^{1}$, TAO ZHANG $^{3}$, YANQING CHI $^{3}$ and FENG GAO $^{1}$ \\ ${ }^{1}$ Department of Pathology, The Third Hospital of Hebei Medical University, Shijiazhuang, Hebei 050051; \\ ${ }^{2}$ Department of Biochemistry, Hebei Medical University, Shijiazhuang, Hebei 050017; ${ }^{3}$ Department of Nephrology, \\ The Third Hospital of Hebei Medical University, Shijiazhuang, Hebei 050051, P.R. China
}

Received September 26, 2014; Accepted April 15, 2015

DOI: $10.3892 /$ ijmm.2015.2193

\begin{abstract}
The Notch pathway is known to contribute to the development of glomerular disease. Angiotensin II (Ang II), an important member of the renin-angiotensin system, stimulates the accumulation of extracellular matrix components in glomerular disease; however, the exact mechanisms involved remain to be elucidated. In the present study, we aimed to investigate the effects of the Notch pathway on the synthesis of extracellular matrix components in Ang II-stimulated podocytes. Mouse podocytes were stimulated with Ang II $\left(10^{-6} \mathrm{~mol} / \mathrm{l}\right)$. The activation of the Notch pathway was inhibited by a vector carrying short hairpin RNA (shRNA) targeting Notch1 (sh-Notch1) or by $\gamma$-secretase inhibitor (GSI). The protein levels of Notch1, Notch intracellular domain 1 (NICD1), hairy and enhancer of split-1 (Hes1), matrix metalloproteinase (MMP)-2, MMP-9, transforming growth factor- $\beta 1$ (TGF- $\beta 1$ ), type IV collagen and laminin were determined by western blot analysis. The Notch1, Hes1, MMP-2, MMP-9, TGF- $\beta 1$, type IV collagen and laminin mRNA levels were detected by RT-PCR. The MMP-2 and MMP-9 activity was measured using a cell active fluorescence assay kit. The levels of TGF- $\beta 1$, type IV collagen and laminin were determined in the culture medium of the podocytes by enzyme-linked immunosorbent assay (ELISA). Our results revealed that Ang II upregulated Notch1, NICD1, Hes1, TGF- $\beta 1$, type IV collagen and laminin expression and downregulated MMP-2 and MMP-9 expression in the cultured podocytes. The inhibition of the Notch pathway by sh-Notch1 or GSI increased MMP-2 and MMP-9 expression, decreased the TGF- $\beta 1$ level and suppressed type IV collagen and laminin expression. The inhibition of the Notch pathway by sh-Notch1 or GSI also increased MMP-2 and MMP-9 activity, and decreased TGF- $\beta 1$ levels, type IV collagen levels and laminin secretion.
\end{abstract}

Correspondence to: Dr Feng Gao, Department of Pathology, The Third Hospital of Hebei Medical University, 139 Ziqiang Road, Shijiazhuang, Hebei 050051, P.R. China

E-mail: alan846829@163.com

Key words: angiotensin II, Notch pathway, extracellular matrix accumulation, matrix metalloproteinases, podocytes, transforming growth factor- $\beta 1$
These findings indicate that the Notch pathway potentially mediates the Ang II-induced synthesis of extracellular matrix components in podocytes through the regulation of MMPs and TGF- $\beta 1$.

\section{Introduction}

It is considered that the dysfunction of podocytes, which are a type of glomerular epithelial cell, plays an important role in progressive renal diseases, including focal segmental glomerulosclerosis (FSGS) and diabetic nephropathy (DN) $(1,2)$. Podocyte injury is also associated with a higher degree of albuminuria and leads to the development of glomerulosclerosis. It has recently been demonstrated that the Notch pathway plays an important role in the onset and development of glomerular disease (3). Niranjan et al (4) reported that the Notch pathway was activated in podocytes in patients with FSGS and DN and in mouse models of these diseases. The Notch pathway is an evolutionarily conserved and widely used intercellular signaling pathway that influences cellular proliferation and differentiation $(5,6)$. The binding of a ligand induces a conformational change in the Notch receptor. This allows an extracellular metalloprotease to cleave the receptor, which then allows the $\gamma$-secretase-mediated protease to release the Notch intracellular domain (NICD). NICD travels into the nucleus where it activates the transcription of downstream genes, such as the hairy and enhancer of split (Hes) gene.

It is known that alterations in hemodynamics contribute to the development of glomerular disease. Alterations in hemodynamics in glomerular disease activate angiotensin II (Ang II), an important member of the renin-angiotensin system, which damages podocytes and results in the accumulation of extracellular matrix (ECM) components and basement membrane thickening in the glomeruli $(7,8)$. It is well recognized that in glomerular disease, Ang II increases the synthesis of ECM components, including collagens and laminin $(9,10)$. Koshizaka et al (11) found that Ang II induced podocyte apoptosis through the activation of the Notch pathway in cultured podocytes. However, it is unclear as to whether the Notch pathway mediates the Ang II-induced ECM synthesis in podocytes.

Matrix metalloproteinases (MMPs) constitute a family of extracellular soluble or membrane-bound proteases that 
collectively degrade or proteolytically modify essentially all the main components of the ECM, including collagens, laminin and proteoglycans. Gelatinases (e.g., MMP-2 and MMP-9), which degrade type IV collagen and laminin, are important constitutional elements of the basement membrane of the glomeruli $(12,13)$. It is well established that transforming growth factor- $\beta 1$ (TGF- $\beta 1$ ) is a potent stimulator of ECM production in glomerular injury and may be the most important growth factor in determining the extent of renal fibrosis following injury. The exposure of cultured podocytes and mesangial cells to TGF- $\beta 1$ has been shown to increase the production of type IV collagen and laminin (14-16). Previous studies have demonstrated that Ang II decreases matrix degradation due to a reduction in MMP activity and promotes the synthesis of ECM components through TGF- $\beta 1(17,18)$.

In the present study, we aimed to investigate the hypothesis that Ang II may induce the activation of the Notch pathway in podocytes. The activation of the Notch pathway may alter the production of ECM through MMPs and TGF- $\beta 1$ in Ang II-stimulated podocytes. The inhibition of the activation of the Notch pathway can prevent ECM accumulation and glomerulosclerosis.

\section{Materials and methods}

Cell culture. Conditionally immortalized mouse podocytes were purchased from the Cell Resource Center (Peking Union Medical College, Beijing, China). In this cell line, a temperature-sensitive mutant of the SV40 virus large T-cell antigen (tsA58 Tag) is controlled by a $\gamma$-interferon-inducible $\mathrm{H}-2 \mathrm{~K}^{\mathrm{b}}$ promoter. The podocytes were firstly cultured in RPMI1640 medium supplemented with $10 \%$ fetal bovine serum (FBS) (both from Gibco-BRL, Gaithersburg, MD, USA) and $10 \mathrm{U} / \mathrm{ml} \gamma$-interferon (PeproTech, Rochy Hill, NJ, USA) in a $33^{\circ} \mathrm{C} 5 \% \mathrm{CO}_{2}$ atmosphere to induce proliferation, and were then incubated in RPMI-1640 medium supplemented with $10 \%$ FBS and deprived of $\gamma$-interferon in a $37^{\circ} \mathrm{C} 5 \% \mathrm{CO}_{2}$ atmosphere for 14 days to induce quiescence and the differentiated phenotype, as previously described (19). The podocytes were grown to $75-85 \%$ confluence under growth restrictive conditions and growth-arrested in serum-free RPMI-1640 for $24 \mathrm{~h}$ to synchronize cell growth. After this time period, the medium was changed to fresh serum-free medium containing Ang II (10-6 mol/l; Sigma, St. Louis, MO, USA) at the indicated time points, as previously described (11). The transient transfection of the podocytes with a vector carrying short hairpin RNA (shRNA) targeting Notch1 (sh-Notch1) or a negative control vector (sh-Scramble) (Jingsai Corp., Wuhan, China) was carried out using Lipofectamine 2000 (Invitrogen, Carlsbad, CA, USA) according to the manufacturer's instructions. For inhibition experiments, the cells were treated with $\gamma$-secretase inhibitor (GSI; Sigma) at $1 \mu \mathrm{mol} / 1$ for $30 \mathrm{~min}$ prior to stimulation with Ang II.

Western blot analysis. The cells were lysed in lysis buffer (20 mmol/1 Tris $\cdot \mathrm{HCl}, 2.5 \mathrm{mmol} / 1$ EDTA, $10 \%$ glycerol, $0.1 \%$ SDS, $1 \%$ Triton $\mathrm{X}-100,1 \%$ sodium deoxycholate, $10 \mathrm{mmol} / \mathrm{l}$ sodium pyrophosphate, $50 \mathrm{mmol} / \mathrm{l} \mathrm{NaF}, 1 \mathrm{mmol} / \mathrm{l}$ sodium vanadate and $1 \mathrm{mmol} / \mathrm{l} \mathrm{PMSF}$ ) and the protein concentrations were measured by Coomassie brilliant blue assay. Protein $(40 \mu \mathrm{g})$ was loaded and separated on a SDS-polyacrylamide gel and then transferred onto a polyvinylidene fluoride (PVDF) membrane (Millipore Corp., Billerica, MA, USA). The membrane was blocked with 5\% dry milk and incubated overnight at $4^{\circ} \mathrm{C}$ with rabbit anti-Notch1 (ab65297; 1:200 dilution), anti-NICD1 (ab52301; 1:200 dilution), anti-Hes1 (ab71599; 1:2,000 dilution) (all from Abcam, Cambridge, MA, USA), anti-MMP-2 (10737-2-AP; 1:500 dilution; Proteintech, Chicago, IL, USA), anti-MMP-9 (sc-10737; 1:400 dilution; Santa Cruz Biotechnology, Inc., Santa Cruz, CA, USA), anti-TGF- $\beta 1$ (18978-1-AP; 1:1,000 dilution), anti-type IV collagen (19797-1-AP; 1:1,000 dilution), anti-laminin (19698-1-AP; 1:1,000 dilution) (all from Proteintech) and anti- $\beta$-actin (sc-130656; 1:1,000 dilution; Santa Cruz Biotechnology, Inc.) polyclonal antibodies. After washing, the membrane was incubated with goat anti-rabbit IgG horseradish peroxidase conjugate (SA00001-2; 1:5,000 dilution; Proteintech). Proteins in western blot analysis were quantified following acquisition and analysis of the image using the software of a UVP Image Station Lab Works version 4.5. Proteins expression was quantified by comparison with the internal control, $\beta$-actin.

Reverse transcription PCR (RT-PCR). Total RNA was extracted from the podocytes using TRIzol reagent (Invitrogen) according to the instructions of the manufacturer and reverse transcribed using oligo(dT) primers in the presence of avian myeloblastosis virus reverse transcriptase to yield cDNA. The cDNA was amplified on a 7900HT Sequence Detection system (Applied Biosystems, Foster City, CA, USA) at default thermal cycling conditions: $2 \mathrm{~min}$ at $50^{\circ} \mathrm{C}, 10 \mathrm{~min}$ at $95^{\circ} \mathrm{C}$ for enzyme activation and then 40 cycles of $15 \mathrm{sec}$ at $95^{\circ} \mathrm{C}$ for denaturation and $1 \mathrm{~min}$ at $60^{\circ} \mathrm{C}$ for annealing and extension. The results were analyzed using the relative standard curve method of analysis $/ \Delta C_{t}$ method of analysis. The primers used for PCR were as follows: $18 \mathrm{~S}$ forward, 5'-CGC CGC TAG AGG TGA AAT TC-3' and reverse, 5'-CCA GTC GGC ATC GTT TAT GG-3' (149 bp); Notch1 forward, 5'-GTG GAT GAC CTA GGC AAG TCG-3' and reverse, 5'-GTC TCC TCC TTG TTG TTC TGC A-3' (118 bp); Hes1 forward, 5'-CAC GAC ACC GGA CAA ACC A-3' and reverse, 5'-GCC GGG AGC TAT CTT TCT TAA GTG-3' (148 bp); MMP-2 forward, 5'-CAG GGA ATG AGT ACT GGG TCT ATT-3' and reverse, 5'-ACT CCA GTT AAA GGC AGC ATC TAC-3' (118 bp); MMP-9 forward, 5'-CAA TCC TTG CAA TGT GGA TG-3' and reverse, 5'-TAA GGA AGG GGC CCT GTA AT-3' (128 bp); TGF- $\beta 1$ forward, 5'-ACC GCA ACA ACG CAA TCT ATG-3' and reverse, 5'-ATT CCG TCT CCT TGG TTC AG-3' (196 bp); type IV collagen forward, 5'-GTC AAA CTA CTG CTA TCC CTC CGT GTC-3' and reverse, 5'-CAT TCT ATA AAT GGA CTG GCT CGG AAT-3' (162 bp); laminin forward, 5'-CCT GCC AAA TTC CTC GGT AAC-3' and reverse, 5'-ACA TCG TAG GCA GAC GGC TG-3' (101 bp).

Enzyme activity assay. The activity of MMP-2 and MMP-9 in the serum-free conditioned medium was assayed using a cell active MMP-2 and MMP-9 fluorescence assay kit (GenMed Scientifics, Arlington, MA, USA), according to the manufacturer's instructions. The relative fluorescence units were determined with an excitation wavelength of $330 \mathrm{~nm}$ and an emission wavelength of $400 \mathrm{~nm}$. The consistency of the fluorescent polypeptide segments was calculated on the basis of the 

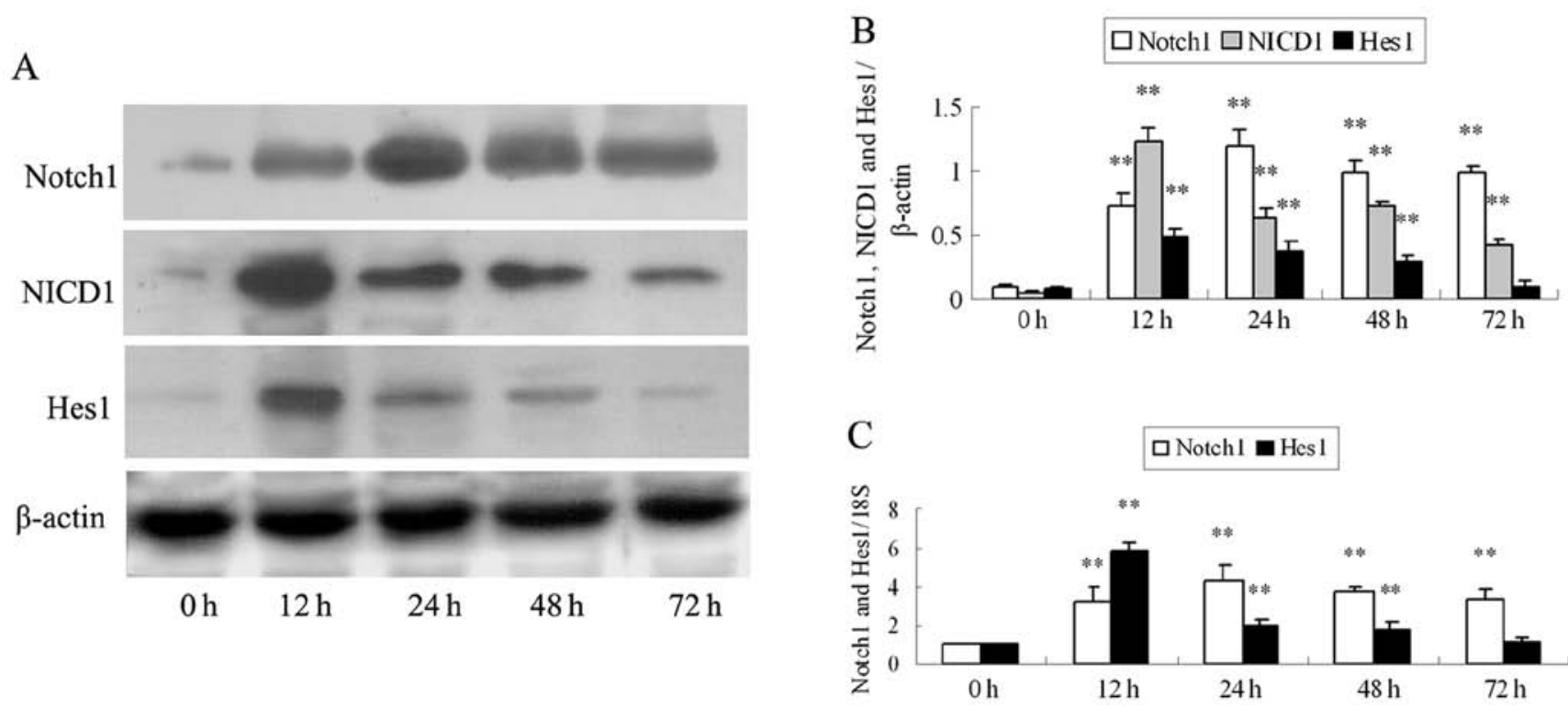

Figure 1. Time course of the activation of the Notch pathway by angiotensin II (Ang II) in podocytes. Podocytes were incubated with Ang II (10 $\left.0^{-6} \mathrm{~mol} / 1\right)$ for $0-72 \mathrm{~h}$. (A) The protein expression of Notch1, Notch intracellular domain 1 (NICD1) and hairy and enhancer of split-1 (Hes1) was measured by western blot analysis. (B) The protein levels of Notch1, NICD1 and Hes1 were quantified by densitometry. Protein expression was normalized to $\beta$-actin. (C) The mRNA expression of Notch1 and Hes1 was detected by RT-PCR. The mRNA expression was normalized to $18 \mathrm{~S}$. Data are presented as the means \pm standard deviation (SD), $\mathrm{n}=6$. ${ }^{* * *} \mathrm{P}<0.01$ vs. Ang II $(0 \mathrm{~h})$.

relative fluorescence units. MMP-2 and MMP-9 activity was expressed as $\mathrm{nmol} / \mathrm{mg} / \mathrm{min}$.

Enzyme-linked immunosorbent assay (ELISA). After the cells were cultured in 6-well plates under the different experimental conditions, the supernatants were collected. The TGF- $\beta 1$, type IV collagen and laminin protein levels were quantified using a commercial quantikine enzyme-linked immunosorbent assay kit (ELISA; R\&D Systems, Minneapolis, MN, USA) according to the manufacturer's instructions.

Statistical analysis. Data presented as bar graphs are the means \pm standard deviation (SD) of at least 3 independent experiments. Statistical analysis was performed using the Student's t-test with SPSS version 13.0 software (SPSS Inc., Chicago, IL, USA). The results were considered statistically significant at $\mathrm{P}<0.05$.

\section{Results}

Ang II activates the Notch pathway in podocytes. To determine the effects of Ang II on the activation of the Notch pathway, we measured the Notch1, NICD1 and Hes1 levels in the podocytes stimulated with Ang II for 0, 12, 24, 48 and 72 h (Fig. 1). Notch1 protein and mRNA expression increased within $12 \mathrm{~h}$ of Ang II stimulation, peaked at $24 \mathrm{~h}$, and then slightly decreased at 48 and $72 \mathrm{~h}$ (all $\mathrm{P}<0.01$ ); the maximum protein expression levels of NICD1 were detected as early as $12 \mathrm{~h}$ and then the expression levels declined, but did not return to the basal levels (Ang II stimulation at $0 \mathrm{~h}$ ) (all $\mathrm{P}<0.01$; Fig. $1 \mathrm{~A}$ and $\mathrm{B})$; Hes1 protein and mRNA expression also peaked at $12 \mathrm{~h}$ and then decreased at 24 and $48 \mathrm{~h}(\mathrm{P}<0.01$; Fig. 1A and $\mathrm{C})$. No changes in Hes1 protein and mRNA expression were detected in the cultured podocytes at 0 and $72 \mathrm{~h}(\mathrm{P}>0.05$; Fig. 1$)$.
Transfection with sh-Notchl or pre-treatment with GSI increases MMP and decreases TGF- $\beta 1$ expression in the Ang II-stimulated podocytes. Compared with the cells stimulated with Ang II at $0 \mathrm{~h}$, the protein levels of Notch1, NICD1 and Hes1 significantly increased at $12 \mathrm{~h}$ (Fig. $2 \mathrm{~A}$ and $\mathrm{B}$; all $\mathrm{P}<0.01$ ). Transfection with sh-Notch1 decreased the Ang II-induced the protein overexpression of Notch1, NICD1 and Hes1 in the podocytes (all $\mathrm{P}<0.01$; Fig. $2 \mathrm{~A}$ and B). RT-PCR revealed similar changes in Notch1 and Hes1 mRNA expression following transfection (Fig. 2C). GSI decreased the NICD1 and Hes1 protein and the Hes1 mRNA expression in the podocytes stimulated with Ang II at $12 \mathrm{~h}$ (all P<0.01; Fig. 2). Western blot analysis and RT-PCR revealed that GSI did not inhibit Notch1 overexpression induced by Ang II at $12 \mathrm{~h}$ (all $\mathrm{P}>0.05$ ). Ang II stimulation decreased MMP-2 and MMP-9 protein and mRNA expression at $12 \mathrm{~h}$ (all $\mathrm{P}<0.01$; Fig. 3). Compared with the cells stimulated with Ang II, the MMP-2 and MMP-9 protein and mRNA levels significantly increased in the podocytes transfected with sh-Notch1 or pre-treated with GSI (all $\mathrm{P}<0.01$ ). Incubation with Ang II for $12 \mathrm{~h}$ resulted in a significant upregulation in TGF- $\beta 1$ protein and mRNA expression compared with the cells stimulated with Ang II at $0 \mathrm{~h}$ (all $\mathrm{P}<0.01)$. However, the changes observed in the TGF- $\beta 1$ expression level in the Ang II-stimulated podocytes were reversed by transfection with sh-Notch1 or by the addition of GSI to the Ang II culture medium (all $\mathrm{P}<0.01$ ).

Transfection with sh-Notch1 or pre-treatment with GSI increases MMP activity in the Ang II-stimulated podocytes. When the podocytes were incubated with Ang II for $12 \mathrm{~h}$, Ang II markedly decreased MMP-2 and MMP-9 activity. However, transfection with sh-Notch1 or pre-treatment with GSI enhanced the Ang II-induced inhibition of MMP-2 and MMP-9 activity (all $\mathrm{P}<0.01$; Fig. 4). 
A

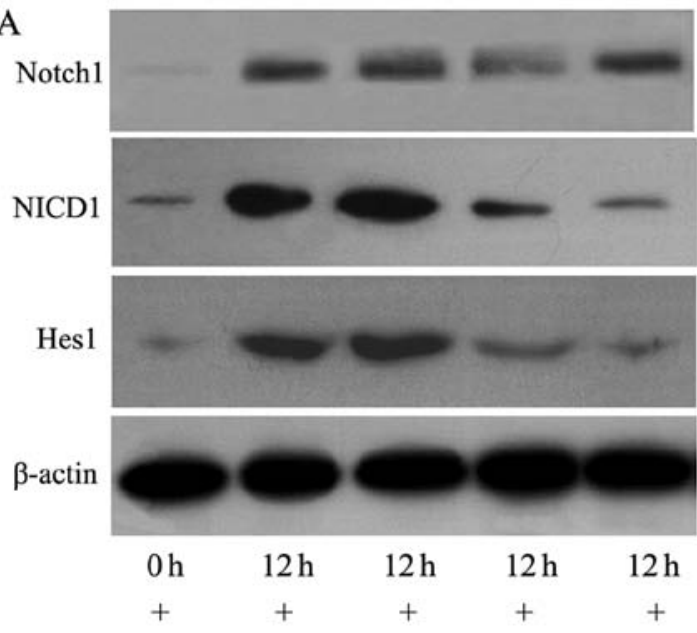

Notransfection Notransfection sh-Scramble sh-Notchl GSI
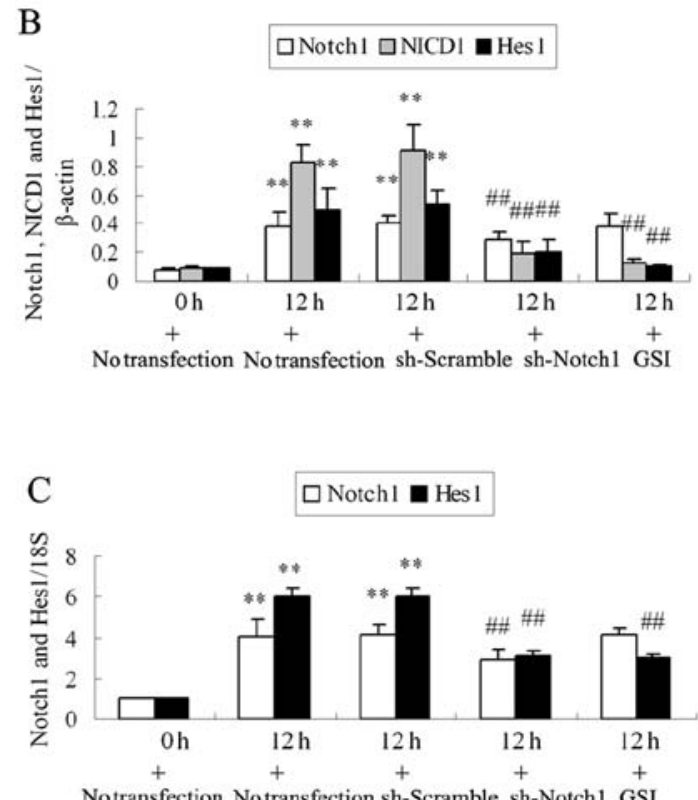

Figure 2. Effect of transfection with short hairpin RNA (shRNA) targeting Notch1 (sh-Notch1) or pre-treatment with $\gamma$-secretase inhibitor (GSI; $1 \mu$ mol/1) on the Notch pathway in angiotensin II (Ang II)-stimulated podocytes. (A) The protein expression of Notch1, Notch intracellular domain 1 (NICD1) and hairy and enhancer of split-1 (Hes1) was measured by western blot analysis. (B) The protein levels of Notch1, NICD1 and Hes1 were quantified by densitometry. Protein expression was normalized to $\beta$-actin. (C) The mRNA levels of Notch1 and Hes1 were detected by RT-PCR. The mRNA expression was normalized to 18S. Data are presented as the means \pm standard deviation (SD), $n=6 .{ }^{* *} \mathrm{P}<0.01$ vs. Ang II $(0 \mathrm{~h}) ;{ }^{\# \#} \mathrm{P}<0.01$ vs. Ang II $(12 \mathrm{~h})+$ sh-Scramble.

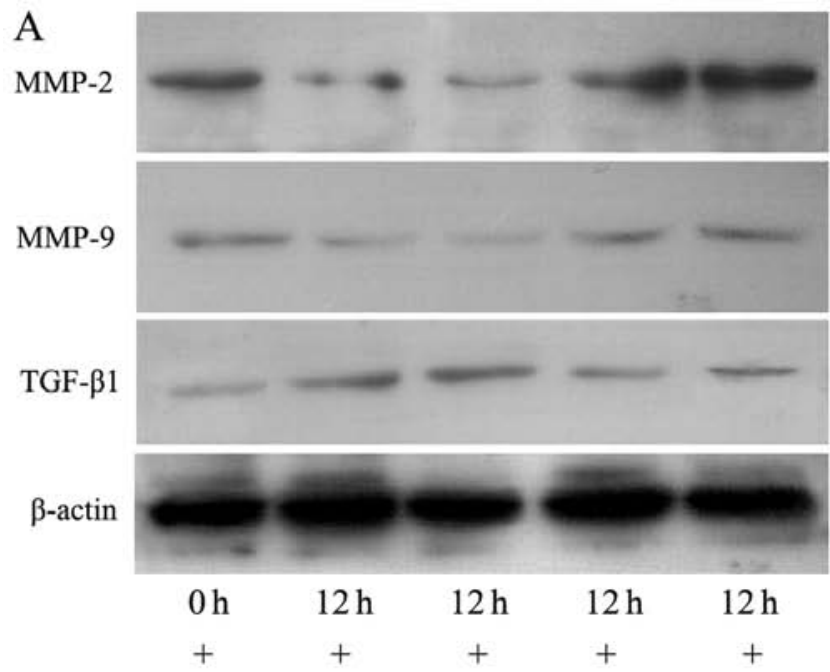

Notransfection Notransfection sh-Scramble sh-Notch1 GSI

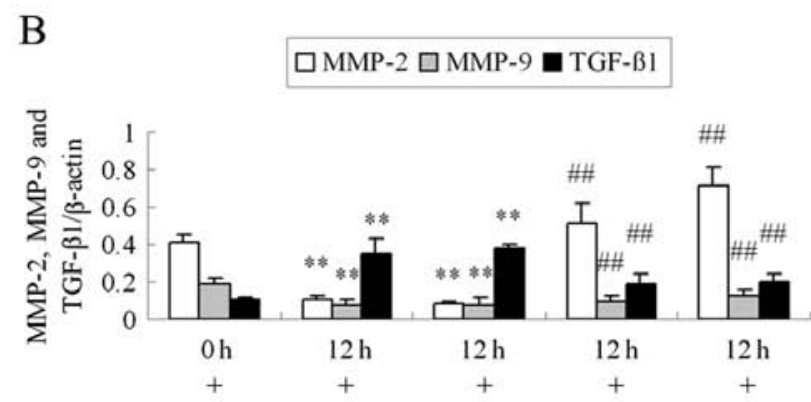

Notransfection Notransfection sh-Scramble sh-Notchl GSI

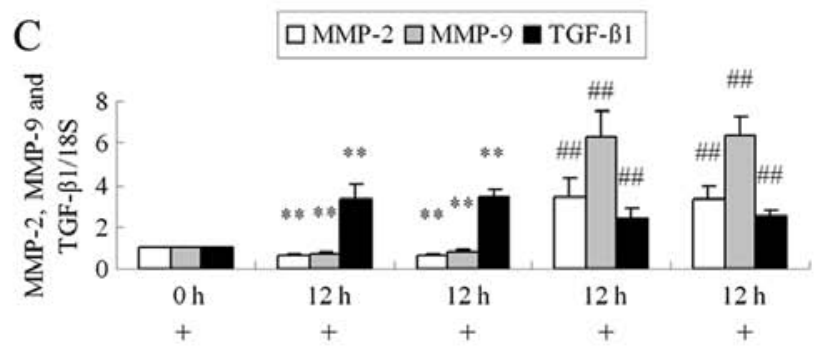

Notransfection Notransfection sh-Scramble sh-Notchl GSI

Figure 3. Effect of transfection with short hairpin RNA (shRNA) targeting Notch1 (sh-Notch1) or pre-treatment with $\gamma$-secretase inhibitor (GSI; $1 \mu$ mol/l) on the expression of matrix metalloproteinase (MMP)-2, MMP-9 and transforming growth factor- $\beta 1$ (TGF- $\beta 1$ ) in angiotensin II (Ang II)-stimulated podocytes. (A) The protein expression of MMP-2, MMP-9 and TGF- $\beta 1$ was measured by western blot analysis. (B) The protein levels of MMP-2, MMP-9 and TGF- $\beta 1$ were quantified by densitometry. Protein expression was normalized to $\beta$-actin. (C) The mRNA levels of MMP-2, MMP-9 and TGF- $\beta 1$ were detected by RT-PCR. The mRNA expression was normalized to $18 \mathrm{~S}$. Data are presented as the means \pm standard deviation (SD), $\mathrm{n}=6 .{ }^{* *} \mathrm{P}<0.01 \mathrm{vs}$. Ang II $(0 \mathrm{~h}) ;{ }^{\# *} \mathrm{P}<0.01 \mathrm{vs}$. Ang II (12 h) + sh-Scramble. 


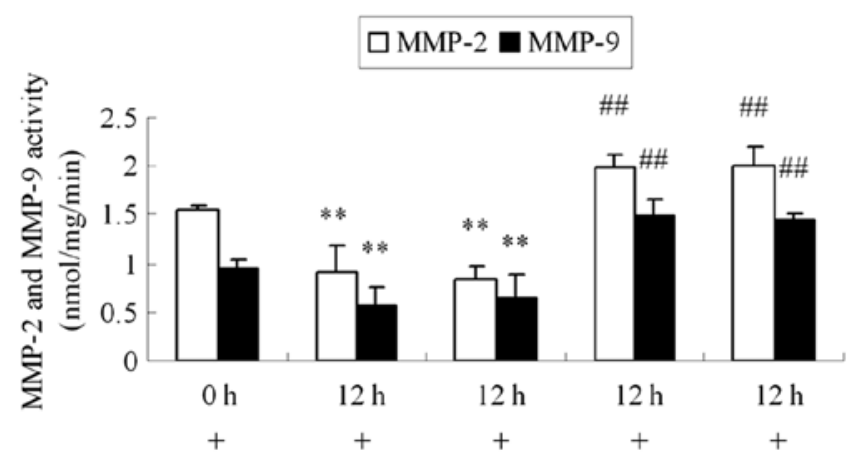

Notransfection Notransfection sh-Scramble sh-Notch1 GSI

Figure 4. Effect of transfection with short hairpin RNA (shRNA) targeting Notch1 (sh-Notch1) or pre-treatment with $\gamma$-secretase inhibitor (GSI; $1 \mu \mathrm{mol} / \mathrm{l}$ ) on the activity of matrix metalloproteinase (MMP)-2 and MMP-9 in angiotensin II (Ang II)-stimulated podocytes. Data are presented as the means \pm standard deviation $(\mathrm{SD}), \mathrm{n}=6 .{ }^{* *} \mathrm{P}<0.01$ vs. Ang II $(0 \mathrm{~h})$; ${ }^{\# \#} \mathrm{P}<0.01$ vs. Ang II (12 h) + sh-Scramble.

expression was induced by Ang II at $12 \mathrm{~h}$ compared with the podocytes treated with Ang II at $0 \mathrm{~h}$; these expression levels were efficiently inhibited by transfection with sh-Notch1 or pre-treatment with GSI $(\mathrm{P}<0.05$ or $\mathrm{P}<0.01)$. Compared with the podocytes stimulated with Ang II at $0 \mathrm{~h}$, the mRNA levels of type IV collagen and laminin were increased in the Ang II-stimulated podocytes at $12 \mathrm{~h}$. Their mRNA expression was inhibited following transfection with sh-Notch1 or pretreatment with GSI (all P<0.01; Fig. 5C).
Transfection with sh-Notchl or pre-treatment with GSI decreases Ang II-induced TGF- $\beta 1$, type IV collagen and laminin secretion. We also examined the concentrations of TGF- $\beta 1$, type IV collagen and laminin in the culture medium of the podocytes using ELISA (Fig. 6). We found that the podocytes stimulated with Ang II for $12 \mathrm{~h}$ showed higher levels of TGF- $\beta 1$, type IV collagen and laminin in the supernatants than those cultured with Ang II at $0 \mathrm{~h}(\mathrm{P}<0.05$ or $\mathrm{P}<0.01)$. Compared to the podocytes stimulated with Ang II, which induced the overexpression of TGF- $\beta 1$, type IV collagen and laminin in the supernatants, transfection with sh-Notch1 or pre-treatment with GSI significantly decreased the expression of TGF- $\beta 1$, type IV collagen and laminin ( $\mathrm{P}<0.05$ or $\mathrm{P}<0.01$; Fig. 6).

\section{Discussion}

The Notch pathway is an evolutionarily conserved local cellsignaling mechanism that participates in a variety of cellular processes and is important in glomerular development $(20,21)$. It has been found that the activation of the Notch pathway in podocytes plays a role in the development of glomerular disease (4). In our previous study, it was revealed that the activation of the Notch pathway in high glucose-stimulated podocytes altered the apoptotic pathway and induced apoptosis (22). Alterations in hemodynamics in glomerular disease induce higher levels of Ang II, which also interacts with the Notch pathway in podocytes (11). In this study, we also observed the activation of the Notch pathway in Ang II-stimulated podocytes. Notch1 seems to be a modulatory target of Ang II in podocytes. Ang II induces Notch1 cleavage in podocytes and the release of

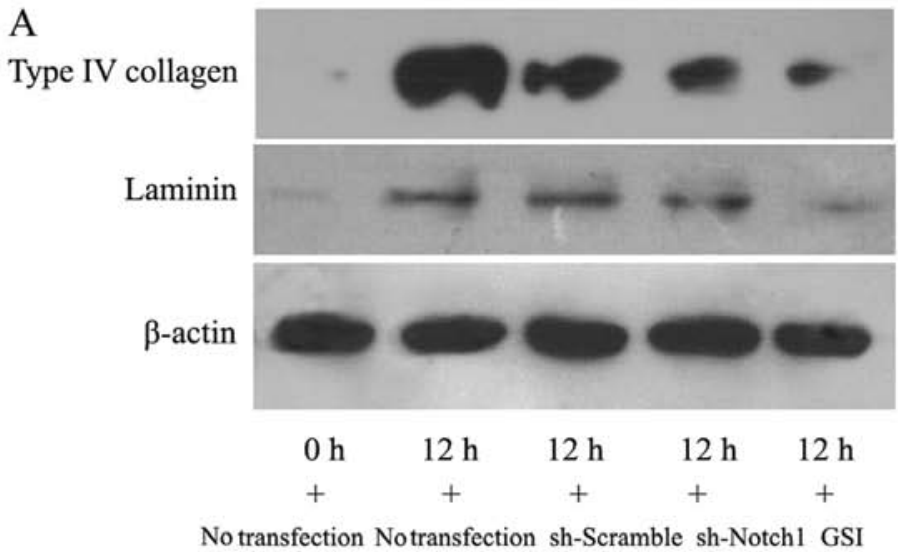

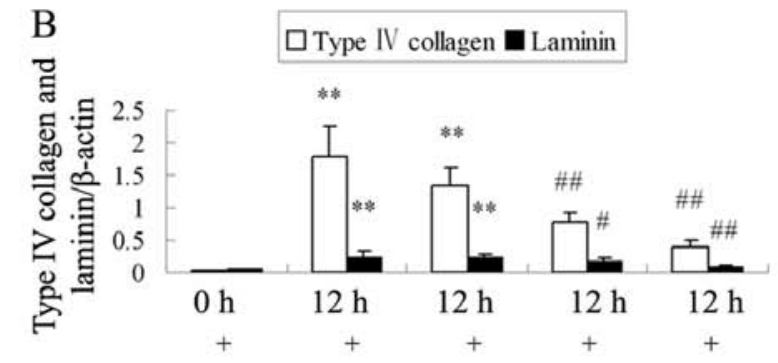

No transfection Notransfection sh-Scramble sh-Notch1 GSI

C

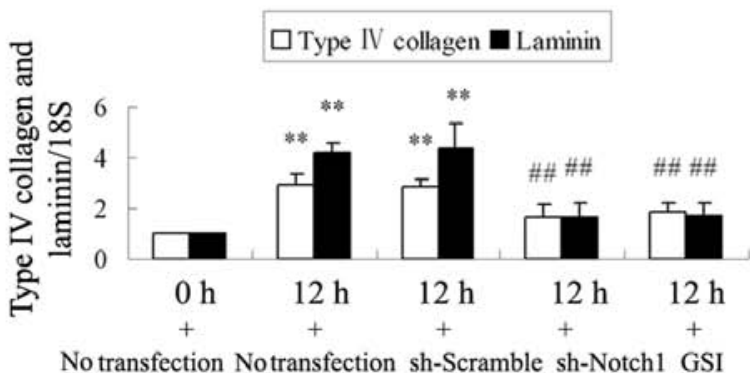

Figure 5. Effect of transfection with short hairpin RNA (shRNA) targeting Notch1 (sh-Notch1) or pre-treatment with $\gamma$-secretase inhibitor (GSI; $1 \mu$ mol/l) on the expression of type IV collagen and laminin in angiotensin II (Ang II)-stimulated podocytes. (A) The protein expression of type IV collagen and laminin was measured by western blot analysis. (B) The protein levels of type IV collagen and laminin were quantified by densitometry. Protein expression was normalized to $\beta$-actin. (C) The mRNA levels of type IV collagen and laminin were detected by RT-PCR. The mRNA expression was normalized to 18S. Data are presented as the means \pm standard deviation $(\mathrm{SD}), \mathrm{n}=6 .{ }^{* *} \mathrm{P}<0.01$ vs. Ang II $(0 \mathrm{~h}) ;{ }^{*} \mathrm{P}<0.05$ and ${ }^{\# \#} \mathrm{P}<0.01$ vs. Ang II $(12 \mathrm{~h})+$ sh-Scramble. 


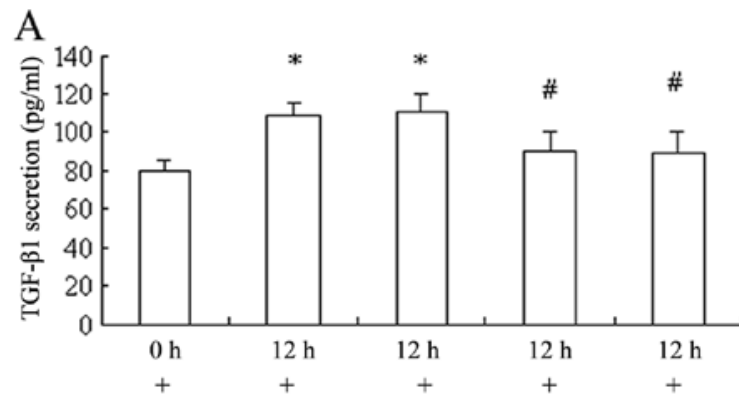

No transfection Notransfection sh-Scramble sh-Notch1 GSI

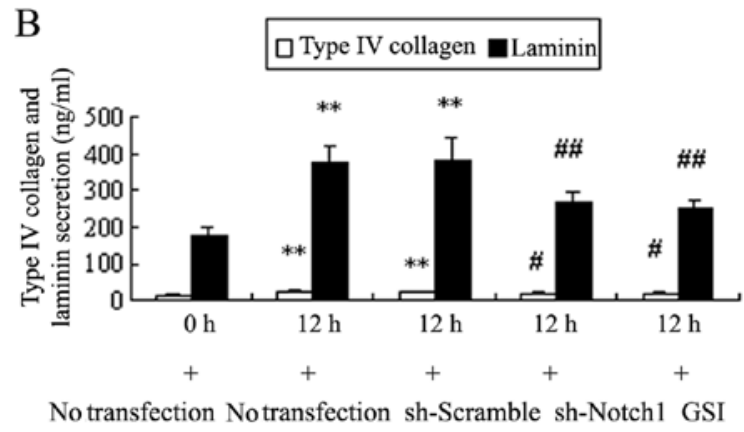

Figure 6. Effect of transfection with short hairpin RNA (shRNA) targeting Notch1 (sh-Notch1) or pre-treatment with $\gamma$-secretase inhibitor (GSI; $1 \mu \mathrm{mol} / \mathrm{l}$ ) on the concentrations of the transforming growth factor- $\beta 1$ (TGF- $\beta 1$ ), type IV collagen and laminin in the culture medium of angiotensin II (Ang II)stimulated podocytes. (A) The protein expression of TGF- $\beta 1$ was analyzed by enzyme-linked immunosorbent assay (ELISA). (B) The protein expression of type IV collagen and laminin was analyzed by ELISA. Data are presented as the means \pm standard deviation (SD), $\mathrm{n}=6 .{ }^{*} \mathrm{P}<0.05,{ }^{* *} \mathrm{P}<0.01$ vs. Ang II $(0 \mathrm{~h})$ ${ }^{\#} \mathrm{P}<0.05$ and ${ }^{\# \#} \mathrm{P}<0.01 v$ s. Ang II $(12 \mathrm{~h})+$ sh-Scramble.

NICD1, which travels to the nucleus where it activates the Hes1 gene. The activation of the Notch pathway induced by Ang II was inhibited by Notch1 shRNA or GSI.

ECM accumulation in glomeruli is considered the most common destructive pathway associated with chronic glomerular disease, which is characterized by the remodeling of the interstitial ECM, resulting in the excessive deposition of ECM components, including type IV collagen and laminin (23). MMPs are zinc-containing endopeptidases that are involved in the remodeling of the ECM and are crucial for tissue development and homeostasis. MMP-2 and MMP-9 cleave the denatured collagens and laminin, as well as some chemokines. In view of their matrix-degrading capacity, MMP-2 and MMP-9 were originally considered to be beneficial to chronic renal fibrogenesis due to their perceived potential to lessen interstitial matrix accumulation and deposition $(12,13,24)$. Studies on renal fibrosis have demonstrated that a decrease in MMP levels promotes the deposition of ECM in the context of renal fibrosis $(11,25)$. Ang II has been shown to inhibit the angiotensin converting enzyme II (ACE2)-induced MMP-2 activity through the Ang II type-1 receptor (AT1R) and extracellular signal-regulated kinase 1 and 2 (ERK1/2) signaling pathway in human cardiofibroblasts (26). Under normal glucose conditions, Ang II induces a dose-dependent downregulation in MMP-2; on the contrary, MMP-9 is upregulated by Ang II (27). However, we found that Ang II inhibited the protein and mRNA expression, as well as the activity of MMP-2 and MMP-9 in podocytes. An enhanced MMP activity has been shown to be responsible for the development of disease due to their ability to degrade type IV collagen and laminin $(28,29)$. Zhou et al $(30)$ found that the downregulation of Notch1 decreased the migration and invasion capacities of hepatocellular carcinoma cells by regulating CD44v6, E-cadherin, MMP-2, MMP-9 and urokinase-type plasminogen activator (uPA). In this study, after the activation of the Notch pathway was inhibited by Notch1 shRNA or GSI in Ang II-stimulated podocytes, MMP-2 and MMP-9 expression and activity increased. These results indicated that Ang II inhibited MMP-2 and MMP-9 through the Notch pathway in podocytes.

It is well established that TGF- $\beta 1$ is a potent stimulator of ECM production in glomerular injury and may be the most important growth factor in determining the extent of renal fibrosis following injury. It has been demonstrated that TGF- $\beta 1$ mediates the production of type IV collagen and laminin in mesangial cells under conditions of high glucose in vitro (31). The exposure of cultured conditionally immortalized human podocytes to TGF- $\beta 1$ has also been shown to increase the production of the basement membrane components (32). In the present study, we found that the stimulation of podocytes with Ang II induced type IV collagen and laminin accumulation by increasing TGF- $\beta 1$ mRNA and protein synthesis. Ang II has been shown to induce the expression and production of TGF- $\beta 1$ through a mechanism dependent on reactive oxygen species production in mouse skeletal muscle cells (33). In another study, Ang II-induced cardiac hypertrophy and fibrosis were significantly enhanced by the increase in TGF- $\beta 1$ expression in fibroblast growth factor 16 (Fgf16) knockout mice (34). Furthermore, our finding that the inhibition of the Notch pathway by Notch1 shRNA or GSI markedly prevented the Ang II-induced upregulation of TGF- $\beta 1$ suggests that Ang II induces TGF- $\beta 1$ expression through the Notch pathway. Aoyagi-Ikeda et al (35) found that Notch induced myofibroblast differentiation through a TGF- $\beta$-Smad3 pathway that activated SMA gene transcription in alveolar epithelial cells, and increased migratory behavior in pulmonary fibrosis. In a previous study, blocking Notch signaling by the $\gamma$-secretase inhibitor, DAPT, was shown to significantly attenuate liver fibrosis, decrease the expression of TGF- $\beta 1$ and suppress the endothelial-to-mesenchymal transition (EMT) process in a rat hepatic stellate cell line (36). In this study, we found that the activity of MMP- 2 and MMP-9 was reduced, and TGF- $\beta 1$ expression was increased in Ang II-stimulated podocytes. Imbalances between the synthesis and degradation of ECM proteins are considered to play important roles in the progression of glomerular sclerosis in glomerular disease (37).

In conclusion, our data demonstrate that the Ang II-induced activation of the Notch pathway, which inhibited MMP activity, increased TGF- $\beta 1$ expression and increased the synthesis of ECM components in podocytes. Thus, the activation of the Notch pathway plays a role in Ang II-induced glomerular injury. The blockade of the Notch pathway may thus be an effective method for the treatment of glomerular disease.

\section{Acknowledgements}

This study was supported by grants from the Hebei Natural ScienceFoundation of China(H2014206294) and the Department of Health of Hebei Province of China (ZL20140030). 


\section{References}

1. Ikezumi Y, Suzuki T, Karasawa T, Yamada T, Hasegawa H, Nishimura $\mathrm{H}$ and Uchiyama $\mathrm{M}$ : Low birthweight and premature birth are risk factors for podocytopenia and focal segmental glomerulosclerosis. Am J Nephrol 38: 149-157, 2013.

2. Ma R, Liu L, Liu X, Wang Y, Jiang W and Xu L: Triptolide markedly attenuates albuminuria and podocyte injury in an animal model of diabetic nephropathy. Exp Ther Med 6: 649-656, 2013.

3. Sirin Y and Susztak K: Notch in the kidney: development and disease. J Pathol 226: 394-403, 2012.

4. Niranjan T, Bielesz B, Gruenwald A, Ponda MP, Kopp JB, Thomas DB and Susztak K: The Notch pathway in podocytes plays a role in the development of glomerular disease. Nat Med 14: 290-298, 2008

5. Zhou W, Wang G and Guo S: Regulation of angiogenesis via Notch signaling in breast cancer and cancer stem cells. Biochim Biophys Acta 1836: 304-320, 2013.

6. Ji X, Wang Z, Geamanu A, Sarkar FH and Gupta SV: Inhibition of cell growth and induction of apoptosis in non-small cell lung cancer cells by delta-tocotrienol is associated with notch-1 downregulation. J Cell Biochem 112: 2773-2783, 2011.

7. Wang W, Li L, Zhou Z, Gao J and Sun Y: Effect of spironolactone combined with angiotensin-converting enzyme inhibitors and/or angiotensin II receptor blockers on chronic glomerular disease. Exp Ther Med 6: 1527-1531, 2013.

8. Ding Y, Stidham RD, Bumeister R, Trevino I, Winters A, Sprouse M, Ding M, Ferguson DA, Meyer CJ, Wigley WC and Ma R: The synthetic triterpenoid, RTA 405, increases the glomerular filtration rate and reduces angiotensin II-induced contraction of glomerular mesangial cells. Kidney Int 83 845-854, 2013

9. Siragy HM and Carey RM: Role of the intrarenal reninangiotensin-aldosterone system in chronic kidney disease. Am J Nephrol 31: 541-550, 2010.

10. Yang S, Yao B,Zhou Y, Yin H,Zhang MZand Harris RC: Intrarenal dopamine modulates progressive angiotensin II-mediated renal injury. Am J Physiol Renal Physiol 302: F742-F749, 2012.

11. Koshizaka M, Takemoto M, Sato S, Tokuyama H, Fujimoto M, Okabe E, Ishibashi R, Ishikawa T, Tsurutani Y, Onishi S, Mezawa M, He P, Honjo S, Ueda S, Saito Y and Yokote K: An angiotensin II type 1 receptor blocker prevents renal injury via inhibition of the Notch pathway in Ins2 Akita diabetic mice. Exp Diabetes Res 2012: 159874, 2012.

12. Zhou TB, Qin YH, Lei FY, Su LN, Zhao YJ and Huang WF: Less gelatinases is associated with apolipoprotein $\mathrm{E}$ accumulation in glomerulosclerosis rats. Histol Histopathol 27: 249-256, 2012.

13. Ji L, Yin XX, Wu ZM, Wang JY, Lu Q and Gao YY: Ginkgo biloba extract prevents glucose-induced accumulation of ECM in rat mesangial cells. Phytother Res 23: 477-485, 2009.

14. Wang B, Komers R, Carew R, Winbanks CE, Xu B, HermanEdelstein M, Koh P, Thomas M, Jandeleit-Dahm K, Gregorevic P, Cooper ME and Kantharidis P: Suppression of microRNA-29 expression by TGF- $\beta 1$ promotes collagen expression and renal fibrosis. J Am Soc Nephrol 23: 252-265, 2012.

15. Schena FP and Gesualdo L: Pathogenetic mechanisms of diabetic nephropathy. J Am Soc Nephrol 16 (Suppl 1): S30-S33, 2005.

16. Singh LP, Green K, Alexander M, Bassly S and Crook ED Hexosamines and TGF-betal use similar signaling pathways to mediate matrix protein synthesis in mesangial cells. Am J Physiol Renal Physiol 286: F409-F416, 2004.

17. Han SY, Jee YH, Han KH, Kang YS, Kim HK, Han JY, Kim YS and Cha DR: An imbalance between matrix metalloproteinase-2 and tissue inhibitor of matrix metalloproteinase- 2 contributes to the development of early diabetic nephropathy. Nephrol Dial Transplant 21: 2406-2416, 2006.

18. Liu GX, Li YQ, Huang XR, Wei L, Chen HY, Shi YJ, Heuchel RL and Lan HY: Disruption of Smad7 promotes Ang II-mediated renal inflammation and fibrosis via Sp1-TGF- $\beta / \mathrm{Smad} 3-\mathrm{NF}-\kappa \mathrm{B}-$ dependent mechanisms in mice. PLoS One 8: e53573, 2013.

19. Mundel P, Reiser J, Zúñiga Mejía Borja A, Pavenstädt H, Davidson GR, Kriz W and Zeller R: Rearrangements of the cytoskeleton and cell contacts induce process formation during differentiation of conditionally immortalized mouse podocyte cell lines. Exp Cell Res 236: 248-258, 1997.
20. Cheng HT, Kim M, Valerius MT, Surendran K, SchusterGossler K, Gossler A, McMahon AP and Kopan R: Notch2, but not Notch1, is required for proximal fate acquisition in the mammalian nephron. Development 134: 801-811, 2007.

21. Arumugam TV, Chan SL, Jo DG, Yilmaz G, Tang SC, Cheng A, Gleichmann M, Okun E, Dixit VD, Chigurupati S, Mughal MR, Ouyang X, Miele L, Magnus T, Poosala S, Granger DN and Mattson MP: Gamma secretase-mediated Notch signaling worsens braindamage and functional outcome in ischemic stroke. Nat Med 12: 621-623, 2006.

22. Gao F, Yao M, Shi Y, Hao J, Ren Y, Liu Q, Wang X and Duan H: Notch pathway is involved in high glucose-induced apoptosis in podocytes via Bcl-2 and p53 pathways. J Cell Biochem 114: 1029-1038, 2013

23. Lennon R, Byron A, Humphries JD, Randles MJ, Carisey A, Murphy S, Knight D, Brenchley PE, Zent R and Humphries MJ: Global analysis reveals the complexity of the human glomerular extracellular matrix. J Am Soc Nephrol 25: 939-951, 2014.

24. Cheng S, Pollock AS, Mahimkar R, Olson JL and Lovett DH: Matrix metalloproteinase 2 and basement membrane integrity: a unifying mechanism for progressive renal injury. FASEB J 20: 1898-1900, 2006.

25. Tsai JP, Liou JH, Kao WT, Wang SC, Lian JD and Chang HR: Increased expression of intranuclear matrix metalloproteinase 9 in atrophic renal tubules is associated with renal fibrosis. PLoS One 7: e48164, 2012.

26. Kuan TC, Chen MY, Liao YC, Ko L, Hong YH, Yen CY, Hsieh WY, Cheng KS, Wu CL and Lin CS: Angiotensin II downregulates ACE2-mediated enhancement of MMP-2 activity in human cardiofibroblasts. Biochem Cell Biol 91: 435-442, 2013.

27. Solini A, Rossi C, Santini E, Madec S, Salvati A and Ferrannini E: Angiotensin-II and rosuvastatin influence matrix remodeling in human mesangial cells via metalloproteinase modulation. J Hypertens 29: 1930-1939, 2011.

28. Czech KA, Bennett M and Devarajan P: Distinct metalloproteinase excretion patterns in focal segmental glomerulosclerosis. Pediatr Nephrol 26: 2179-2184, 2011.

29. Sun H, Ge N, Shao M, Cheng X, Li Y, Li S and Shen J: Lumbrokinase attenuates diabetic nephropathy through regulating extracellular matrix degradation in Streptozotocin-induced diabetic rats. Diabetes Res Clin Pract 100: 85-95, 2013.

30. Zhou L, Zhang N, Song W, You N, Li Q, Sun W, Zhang Y, Wang D and Dou K: The significance of Notch1 compared with Notch3 in high metastasis and poor overall survival in hepatocellular carcinoma. PLoS One 8: e57382, 2013.

31. Tang DQ, Wei YQ, Yin XX, Lu Q, Hao HH, Zhai YP, Wang JY and Ren J: In vitro suppression of quercetin on hypertrophy and extracellular matrix accumulation in rat glomerular mesangial cells cultured by high glucose. Fitoterapia 82: 920-926, 2011.

32. Herman-Edelstein M, Thomas MC, Thallas-Bonke V, Saleem M, Cooper ME and Kantharidis P: Dedifferentiation of immortalized human podocytes in response to transforming growth factor- $\beta$ : a model for diabetic podocytopathy. Diabetes 60: 1779-1788, 2011.

33. Morales MG, Abrigo J, Meneses C, Simon F, Cisternas F, Rivera JC, Vazquez Y and Cabello-Verrugio C: The Ang-(1-7)/Mas-1 axis attenuates the expression and signalling of TGF- $\beta 1$ induced by AngII in mouse skeletal muscle. Clin Sci (Lond) 127: 251-264, 2014.

34. Matsumoto E, Sasaki S, Kinoshita H, Kito T, Ohta H, Konishi M, Kuwahara K, Nakao K and Itoh N: Angiotensin II-induced cardiac hypertrophy and fibrosis are promoted in mice lacking Fgf16. Genes Cells 18: 544-553, 2013.

35. Aoyagi-Ikeda K, Maeno T, Matsui H, Ueno M, Hara K, Aoki Y, Aoki F, Shimizu T, Doi H, Kawai-Kowase K, Iso T, Suga T, Arai M and Kurabayashi M: Notch induces myofibroblast differentiation of alveolar epithelial cells via transforming growthfactor- $\{$ beta $\}$ Smad3 pathway. Am J Respir Cell Mol Biol 45: 136-144, 2011.

36. Chen Y, Zheng S, Qi D, Zheng S, Guo J, Zhang S and Weng Z: Inhibition of Notch signaling by a $\gamma$-secretase inhibitor attenuates hepatic fibrosis in rats. PLoS One 7: e46512, 2012.

37. Tsioufis C, Bafakis I, Kasiakogias A and Stefanadis C: The role of matrix metalloproteinases in diabetes mellitus. Curr Top Med Chem 12: 1159-1165, 2012. 